\title{
Distribution of Scaphoid Nutrient Foramina
}

\author{
Patricia Quinn Owira, James Kigera, Hassan Saidi
}

School of Medicine, University of Nairobi

Correspondence to: Dr. James Kigera, P.0 Box 30196-00100 Nairobi. Email: jameskigera@yahoo.co.uk

\begin{abstract}
Introduction: Avascular necrosis (AVN) is a frequent complication of scaphoid fractures especially those involving the proximal segment of the bone. This has been attributed to its precarious blood supply which is further compromised by the fracture and surgery. Knowledge of the distribution of scaphoid nutrient foramina, which show variation across populations, is thus important in estimating the risk of vascular damage during surgical approaches and hence the likelihood of AVN. It may also be useful in determining techniques to mitigate this risk. The purpose of this study was to describe the distribution of scaphoid nutrient foramina in adult Kenyans. Methods: One hundred and four human scaphoids were studied. Each was divided into 3 segments: proximal, middle and distal, and the nutrient foramina in each segment counted and categorized into type I (no foramina),
\end{abstract}

\section{Introduction}

Scaphoid fractures are common injuries representing about $60-70 \%$ of all carpal fractures with approximately $20 \%$ of them occurring at the proximal pole (1-3). These injuries have an increased risk of delayed union and avascular necrosis $(\operatorname{AVN})(4,5)$. AVN has been reported to occur in 13 to $50 \%$ of scaphoid fractures, with an even higher incidence in those involving the proximal segment of the bone $(4,6)$. This has been attributed to the precarious blood supply of this region. The blood supply to the scaphoid comes mainly from the radial artery and the proximal pole has been shown to have limited interosseous supply $(7,8)$. Alternative blood supply comes from the dorsal, laterovolar and distal groups of extraossoeus blood vessels that enter the bone via foramina on the surface of the bone (7). Studying these foraminal pattern can inform on the vascularization of the bone (9). The types of foramina have been previously classified by Dubey et al (9). Knowing the distribution of vascular foramina may aid in evaluating the vascularity of the type II (1-2 foramina) and type III ( $>2$ foramina). The number of nutrient foramina on the dorsal and volar aspects of the bone was also compared. Results: Type I nutrient foramina were most common (54\%) in the proximal segment of the bone while the middle and distal segments had predominantly type III and type II foramina respectively. More foramina were present on the dorsal aspect with a dorsal-volar ratio of 4.23:1. Conclusion: The dorsal approach may result in more damage to nutrient foramina heightening the risk of avascular necrosis. Non-unions in the proximal segment may require vascularized bone grafts.

Keywords: Scaphoid, Nutrient Foramina, Non Union, Avascular Necrosis

Ann Afr Surg. 2016;13(2): 49-51.

DOI: http://dx.doi.org/10.4314/aas.v13i2.3

different segments of the bone. This may be useful in explaining the risk of AVN and in determining the role of vascularised grafts in the management of delayed and non union (9-11). Although the surgical approach to this bone depends on many factors, knowledge of the pattern of blood supply to the volar and dorsal surfaces of the bone may indicate the degree of vascular damage likely to be caused by the chosen surgical approach(12). While some studies have been conducted on vascular foramina, few describe the vascularity per segment and none have been conducted in the African region. This descriptive cross-sectional study therefore sought to describe the distribution of nutrient foramina in the bone in a Kenyan population.

\section{Methods}

One hundred and four dry adult human scaphoids were obtained from the Department of Osteology, National Museums of Kenya, Nairobi. Broken scaphoids and those that showed obvious gross malformations were excluded from the study. The scaphoid was 
divided and demarcated into 3 equal portions: the proximal, middle and distal segments. The number of foramina per segment was then counted on both volar and dorsal surfaces of the bone with the aid of a magnifying lens. The average of two counts was taken to minimize errors. We modified the classification initially proposed by Dubey et al (9). The specimen were categorized into type I (no foramina), type II (1-2 foramina) and type III ( $>2$ foramina).

\section{Results}

There were fifty two pairs of bones; 21 being male, 16 female and 15 of unknown sex. In the proximal segment, type I nutrient foramina were the most common (54\%) with type III nutrient foramina being prevalent in the middle segment (51\%). The distal segment showed a dominance of type II nutrient foramina (52\%) (Table 1). No type I nutrient foramina was observed at the middle and distal segments. The average number of nutrient foramina in the proximal segment was 1 while that in the middle and distal segments was 4 and 3 respectively. There were more nutrient foramina in the dorsal aspect with a dorsalvolar ratio of 4.23:1.

Table 1: Frequency of the Various Types of Nutrient Foramina

\begin{tabular}{|l|l|l|l|}
\hline Segment & $\begin{array}{l}\text { Type I }(0 \\
\text { Foramina })\end{array}$ & $\begin{array}{l}\text { Type II }(1-2 \\
\text { Foramina) }\end{array}$ & $\begin{array}{l}\text { Type III } \\
(>2 \text { Foramina })\end{array}$ \\
\hline $\begin{array}{l}\text { Proximal } \\
\text { (Volar and dorsal) }\end{array}$ & $112(54 \%)$ & $88(42 \%)$ & $8(4 \%)$ \\
\hline $\begin{array}{l}\text { Middle } \\
\text { (Volar and dorsal) }\end{array}$ & $0(0 \%)$ & $101(49 \%)$ & $107(51 \%)$ \\
\hline $\begin{array}{l}\text { Distal } \\
\text { (Volar and dorsal) }\end{array}$ & $0(0 \%)$ & $108(52 \%)$ & $100(48 \%)$ \\
\hline
\end{tabular}

*Each bone is counted twice, once for the dorsal side and once for the volar side

\section{Discussion}

The proximal segment had a more precarious blood supply evidenced by the high frequency of type I nutrient foramina and the lower number of nutrient foramina in the proximal segment. This may explain the increased occurrence of AVN and non union in this segment (4). This is somewhat consistent with the findings by Purushothama et al. that showed 15\% of scaphoids had no nutrient foramina in the proximal segment and also by Ceri et al. that showed that $18 \%$ of scaphoids had no nutrient foramina in the proximal segment $(13,14)$. There is however conflicting data on the vascularity of the bone from other authors who contend that the proximal segment of the scaphoid is well supplied (15). A recent study that used MRI however showed that the proximal segment shows reduced blood supply. This study however failed to demonstrate a relationship between vascularity and fracture healing (16). This probably illustrates that the occurrence of non union and $\mathrm{AVN}$ is a complex process and vascularity is just one of the factors influencing it. The varying results could also be as a result of different techniques by various authors. While counting has consistently shown that the proximal segment has fewer vascular foramina than the distal segment, injecting particulates into vessels to the scaphoid has yielded different results (15). It is likely that some of the vessels that enter the proximal pole are microscopic and do not leave any visible foramina on the dried bone. This may also explain why the blood flow in this region is shown to be limited on MRI despite the finding of blood vessels when injecting techniques are used. Non union and AVN are common after fractures of the proximal segment (4). When non union of proximal segment fractures occurs, good results have been achieved with vascularized bone grafts (17). This gives credence to our contention that vascularity is at the core of the factors that lead to these complications.

There were more nutrient foramina on the dorsal surface with a dorsal-volar ratio of $4.23: 1$ consistent with the findings of Dubey et al. (18). This demonstrates that the scaphoid receives more blood supply from its dorsal aspect. It also agrees with the study by Botte et al. which indicates that the dorsal aspect has the more important blood supply compared to the volar aspect (19). In contrast, however, some authors seem to suggest that the two surfaces have similar blood supply with at least three consistent vessels entering the bone through the volar surface (15). We contend that the presence of vessels may not necessarily mean adequate vascularity and perfusion studies may help elucidate this area. Studies have demonstrated that percutaneous placement of screws from either the dorsal or volar aspect may affect various neurovascular and tendinous structures and recommend the use of mini open incisions $(20,21)$. This would be accompanied by more soft tissue injury including injury to the vasculature to the bone and it may be prudent to use the approach that reduces this risk. Though there are several factors that influence the choice of surgical approach, the results of this study suggest that a volar approach to the scaphoid limits the extent of injury of the blood supply to the bone.

\section{Conclusion}

The paucity of nutrient foramina in the proximal scaphoid segment provides an anatomical basis for the increased incidence of $\mathrm{AVN}$ and gives credence to the need for vascularized bone grafts in the management of delayed and non-unions in this segment. Although 
the scaphoid can be approached from either the dorsal or volar aspect, this study suggests that the vascularity of the bone would be least traumatized following a volar approach.

\section{Limitations}

The material used for the study was drawn from a select population of Kenyans and therefore may not have been a true representation of the Kenyan population.

\section{References}

1. Varga P, Schefzig P, Unger E, et al. Finite Element Based Estimation of Contact Areas and Pressures of the Human Scaphoid in Various Functional Positions of the Hand. J Biomech. 2013;46(5):984-90.

2. Hove LM. Epidemiology of Scaphoid Fractures in Bergen, Norway. Scand J Plast Reconstr Surg Hand Surg. 1999;33(4):423-6.

3. Larsen CF, Brondum V, Skov O. Epidemiology of Scaphoid Fractures in Odense, Denmark. Acta Orthop Scand. 1992;63(2):216-8.

4. Steinmann SP, Adams JE. Scaphoid Fractures and Nonunions: Diagnosis and Treatment. J Orthop Sci. 2006;11(4):424-31.

5. Barton NJ. The Late Consequences of Scaphoid Fractures. J Bone Joint Surg Br. 2004;86(5): 626-30.

6. Herbert TJ, Fisher WE. Management of the Fractured Scaphoid Using a New Bone Screw. J Bone Joint Surg Br. 1984;66(1):114-23.

7. Taleisnik J, Kelly PJ. The Extraosseous and Intraosseous Blood Supply of the Scaphoid Bone. J Bone Joint Surg Am. 1966;48(6):1125-37.

8. Gelberman RH, Gross MS. The Vascularity of the Wrist. Identification of Arterial Patterns at Risk. Clin Orthop Relat Res. 1986;202:40-9.

9. Dubey PP, Chauhan NK, Siddiqui MS. Vascular Foramina of Scaphoid and its Clinical Implications. Biomedical Research. 2011;22(2):201-4.

10. Merrell GA, Wolfe SW, Slade JF, 3rd. Treatment of Scaphoid Nonunions: Quantitative Meta-Analysis of the Literature. J Hand Surg Am. 2002;27(4): 685-91.
11. Tambe AD, Cutler L, Stilwell J, et al. Scaphoid Non-Union: The Role of Vascularized Grafting in Recalcitrant Non-Unions of the Scaphoid. J Hand Surg Br. 2006;31(2):185-90.

12. Kawamura K, Chung KC. Treatment of Scaphoid Fractures and Nonunions. J Hand Surg Am. 2008;33(6):988-97.

13. Purushothama C, Sarda RK, Konuri A, et al. Morphological and Morphometric Features of Scaphoid Bone in North Eastern Population, India. Nepal Med Coll J. 2011;13(1):20-3.

14. Ceri N, Korman E, Gunal I, et al. The Morphological and Morphometric Features of the Scaphoid. J Hand Surg Br. 2004;29(4):393-8.

15. Oehmke MJ, Podranski T, Klaus R, et al. The Blood Supply of the Scaphoid Bone. J Hand Surg Eur Vol. 2009;34(3): 351-7.

16. Dawson JS, Martel AL, Davis TR. Scaphoid Blood Flow and Acute Fracture Healing. A Dynamic MRI Study with Enhancement with Gadolinium. J Bone Joint Surg Br. 2001;83(6):809-14.

17. Werdin F, Jaminet P, Naegele B, etal. Reconstruction of Scaphoid Nonunion Fractures of the Proximal One Third With a Vascularized Bone Graft From the Distal Radius. Eplasty. 2014;14:e24.

18. Dubey PP, Chauhan NK, Siddiqui MS. Vascular Foramina of Scaphoid and its Clinical Implications. Biomedical Research. 2011;22(2):201-4.

19. Botte MJ, Mortensen WW, Gelberman RH, et al. Internal Vascularity of the Scaphoid in Cadavers after Insertion of the Herbert Screw. J Hand Surg Am. 1988;13(2):216-20.

20. Adamany DC, Mikola EA, Fraser BJ. Percutaneous Fixation of the Scaphoid Through a Dorsal Approach: An Anatomic Study. J Hand Surg Am. 2008;33(3): 327-31.

21. Evans S, Brantley J, Brady C, et al. Structures at Risk During Volar Percutaneous Fixation of Scaphoid Fractures: A Cadaver Study. Iowa Orthop J. 2015;35: 119-23. 